national census 2005 as standard population and grouping by age.

Results In the period from 1979 to 2012 registered 100,420 deaths by suicide, the ratio by sex was 4.8 men by each woman, and the rest was none specified. From 1979 to 1984, the trend was descending ( $p=0.19$ ), but since 1984 to 2012 it was ascending from $1.31 / 100,000$ in 1984 to $3.90 / 100,000$ in 2012 ( $p \leq$ $0.001)$. The mortality trend by sex, in men the mortality rate was ascending from $2.47 / 100,000$ in 1984 to $7.37 / 100,000$ ( $p \leq$ 0.001 ) in 2012. In women, $0.43 / 100,000$ in 1984 to $1.77 /$ $100,000(p \leq 0.001)$ in 2012. In the last 20th years, the age groups with high mortality were 10-14 (57.49\%) and 15-19 $(38.56 \%)$. The states with high mortality rates in 2012 were Aguascalientes, Quintana Roo and Chihuahua, while those with low rates were Guerrero, Oaxaca y Baja California.

Conclusions Suicide is a Public Health problem that increased constantly the last 28 years and it requires a deep analysis of other variables such as mental health, social problems and other kind of problems that affect to individual as well family and society in their psychological well-being.

\section{SURVEILLANCE OF SUICIDE USING ADMINISTRATIVE HEALTH DATABASES: A STUDY IN QUÉBEC AND IN BELGIUM}

${ }^{1,2}$ Christelle Senterre, ${ }^{1}$ Alain Levêque, ${ }^{3}$ Eric Pelletier, ${ }^{3}$ Louis Rochette, ${ }^{3}$ Danielle St-Laurent, ${ }^{2}$ Elham Rahme. 'Université Libre De Bruxelles, School of Public Health, Research Centre in Epidemiology, Biostatistics and Clinical Research, Belgium; ${ }^{2}$ Mc Gill University, Department of Medicine, Division of Clinical Epidemiology, Canada; ${ }^{3}$ Bureau d'Information Et d'Etudes en Santé Des Populations, Institut National De Santé Publique Du Québec, Canada

\subsection{6/injuryprev-2016-042156.564}

Background It is well known that a suicide attempt (SA) is one of the main risk factors for a death from suicide and that some events, as occurrence of injuries can be interpreted as predictive factors of future suicidal behaviours. Surveillance of these types of events would permit to better organise the prevention. The use of health administrative databases may be an interesting source of information that allows a longitudinal surveillance of these events. The aim of this research is to study the occurrence of traumatic (self-inflicted) injuries and (mental) health events over time in the Province of Quebec, Canada and in Belgium.

Methods A retrospective cohort study was first conducted in Quebec and is will be reproduced in Belgium. In Québec, the 2006-2014 data from the SISMACQ (Système intégré de surveillance des maladies chroniques du Québec) database was used; and in Belgium, the RCM (Résumé Clinique Minimum) database will be use. The cohort included all individuals with SA in 20062014 identified from hospital records in SISMACQ using the international classification of disease $10^{\text {th }}$ edition for self-inflicted injury. For each individual, the first SA during a given year was retained (index event). SAs during the year preceding the index event were assessed. Recurrent SAs on a prospective period of 3 years were also assessed. In addition, health care consumption and mortality (all causes and related to suicide) were examined during the three-year period post the index event.

Results The first descriptive analysis of Québec data have identified 11,022 suicide attempts related to 9,755 individuals, meaning that 846 people $(8.7 \%)$ had more than one hospitalisation for SA, with $2.3 \%$ having 3 or more SA during the follow-up period. In $65.6 \%$ of cases, the time between $2 \mathrm{SA}$ was equal or lower than 1 year, while for $17.3 \%$ it was between 1 and 2 years; and for the last $17.1 \%$ it was 3 years or more. Regarding the Belgian data, no result is currently available due to long administrative procedures to obtain them.

Conclusions The use of health administrative databases for the study and surveillance of suicidal behaviours, and of their associated events, allows a better understanding of the suicidal continuum (before - after) and therefore may inform organisation of the universal, selective, and indicated prevention.

\section{ATTENDANCES DUE TO SELF-HARM AND PSYCHIATRIC CONSULTATION RATE IN ONE EMERGENCY DEPARTMENT IN FINLAND}

${ }^{1}$ llona Nurmi-Lüthje, ${ }^{2}$ Jari Hinkkurinen, ${ }^{2}$ Kimmo Salmio, ${ }^{2}$ Lasse Lundell, ${ }^{3}$ KirsiMarja Karjalainen, ${ }^{2}$ Peter Lüthje. 'University of Helsinki, Finland; ${ }^{2}$ North Kymi Hospital, Kouvola, Finland; ${ }^{3}$ City of Kouvola, Finland

\subsection{6/injuryprev-2016-042156.565}

Background There is little recent information on the epidemiology of deliberate self-harm and on

the psychiatric consultation rate in these cases in Finland. Monitoring of self-harm and attempted suicides is insufficient.

Methods on patients attending the emergency department (ED) at North Kymi Hospital due to deliberate self-harm were gathered prospectively for two years. Breath alcohol concentration was measured on admission.

Results A total of 272 cases, 55\% of which occurred in women. The total number of patients was 210 . The rate of repetitions in the total data was $16 \% .71 \%$ of men and $61 \%$ of women were under the influence of alcohol at the time of attendance. The typical patient was a female aged $15-24$ or $40-44$ years, or a male aged 20-29 years, who attended the ED on a weekend night and was under the influence of alcohol. Two out of three cases (184/ 272 ) involved intoxication and most (66\%) were alcohol-related. However, self-cutting was frequent among patients under 20 years of age $(15 / 37,41 \%)$. A psychiatric diagnosis was lacking in two out of three patients. Psychiatric consultation took place in half of the intoxication cases and in one third of the self-cutting cases.

Conclusions Young and middle-aged women and young male adults were at highest risk of deliberate self-harm. Alcohol was strongly associated with self-harm. Psychiatric evaluation and psychiatric consultation varied considerably. Regular monitoring of deliberate self-harm is important in order to follow up trends in mental health and alcohol abuse in the population. The data should be used for prevention and for planning adequate psychiatric consultation and mental health services.

\section{SUICIDES IN SPLIT AND DALMATIA COUNTY, CROATIA, 2004-2013}

Ivana Bocina, Jasna Nincevic, Ingrid Tripkovic. Public Health Institute of Split and Dalmatia County, Croatia

\subsection{6/injuryprev-2016-042156.566}

Background Suicide represents serious public health issue of today. Suicide deaths are largely preventable and subject to public health interventions. Our study based on population mortality data tried to identify the most vulnerable populations with the aim to create specific prevention programs at regional level.

Methods The cross-sectional study was used in this research. Mortality data were collected by the Croatian Bureau of Statistics for Split and Dalmatia County (SDC) population over period 